REFERENCES:

[1] Clauw DJ. Fibromyalgia: a clinical review. JAMA. 2014;311:1547-55.

[2] Nascimento, et al. Gender role in pain perception and expression: an integrative review. BrJP. 2020; 3: 58-62

[3] Wolfe F, et al. Fibromyalgia criteria and severity scales for clinical and epidemiological studies: A modification of the ACR preliminary diagnostic criteria for fibromyalgia. J Rheumatol 2011;38:1113-22.

[4] Burckhardt CS, et al. The fibromyalgia impact questionnaire: development and validation. J Rheumatol 1991;18:728-33.

[5] Salaffi F, et al. Diagnosis of fibromyalgia: comparison of 2011/2016 ACR and AAPT criteria and validation of the modified Fibromyalgia Assessment Status. Rheumatol 2020; 0:1-8.

[6] Wolfe $\mathrm{F}$, et al. Fibromyalgia prevalence, somatic symptom reporting, and the dimensionality of polysymptomatic distress: results from a survey of the general population. Arthritis Care Res. 2013; 65:777-85

Disclosure of Interests: None declared.

DOI: 10.1136/annrheumdis-2021-eular.3482

\section{OP0311 THE ROLE OF COMORBID PATHOLOGY IN THE PROGRESSIVE COURSE OF ANCA-ASSOCIATED SYSTEMIC VASCULITIS}

A. Chudinov ${ }^{1}$, I. Belyaeva ${ }^{2}$, V. Mazurov ${ }^{2}$, O. Inamova ${ }^{1} .{ }^{1}$ Clinical rheumatological hospital \#25, rheumatology, Saint-Peterburg, Russian Federation; ${ }^{2}$ North-West State Medical University named after I.I. Mechnikov, rheumatology, SaintPeterburg, Russian Federation

Background: ANCA-associated systemic vasculitis (AAV) is characterized by a high incidence of complications and high damage index. Comorbid pathology at the onset can significantly worsen the prognosis AAV. The most significant comorbid conditions in patients with AAV are coronary artery disease, hypertension and dyslipidemia.

Objectives: The aim of this study was to determine the role of comorbid pathology in the progressive course in patients with AAV.

Methods: Patients with granulomatosis with polyangiitis (GPA), microscopic polyangiitis (MPA) and eosinophilic granulomatosis with polyangiitis (EGPA) were observed during the first 3 years of the disease and included in this study between 2010 and 2018. At the onset of AAV 75\% of patients had significant comorbidities (coronary artery disease, hypertension, dyslipidemia, chronic obstructive pulmonary disease, peptic ulcer, diabetes mellitus, autoimmune thyroiditis and others).

Results: In total 209 (165 [79\%] female and mean age $51.8 \pm 13.2$ years) AAV patients (94 GPA; 46 MPA; and 69 EGPA) were included in the analysis. Formation of chronic kidney disease was significantly more frequent in the group of AAV patients with hypertension at the onset, than in patients without hypertension (respectively $37 \%$ and $23.6 \%, p=0.041$ ). Development of thromboembolic complications was significantly more frequent in the group of AAV patients with coronary artery disease at the onset of AAV, than in patients without coronary artery disease (respectively $34 \%$ and $14.8 \%, p=0.034$ ). Dyslipidemia also was risk factor for cardiovascular complications $(\mathrm{OR}-3.81,95 \% \mathrm{Cl}(2.43 ; 8.2) \mathrm{p}=0.009)$. Presence of diabetes mellitus in the AAV onset was risk factor for infectious complications (OR - 1.77, 95\% Cl $(1.14 ; 3.45) \mathrm{p}=0.038)$.

Conclusion: Our study has shown that comorbid pathology increase risk of serious complications and can significantly worsen the prognosis AAV. Prevention of development of comorbid conditions and control of lipid levels, hypertension levels are necessary to prevent the formation of irreversible organ damage.

Disclosure of Interests: None declared.

DOI: 10.1136/annrheumdis-2021-eular.4094

\section{Stress, inflammation \& autoimmunity}

\section{OP0312 METABOLIC REPROGRAMMING IN MEMORY CD4+ T CELLS IS ASSOCIATED WITH REACTIVE OXYGEN INDUCED IMMUNE CELL DYSFUNCTION DURING AGING}

Y. Chen ${ }^{1,2}$, Y. Ye $^{3}$, H. Wu ${ }^{4}$, P. L. Krauß $\beta^{1,2}$, P. Löwe ${ }^{1,2}$, M. Pfeiffenberger ${ }^{1,2}$, L. Ehlers ${ }^{1,2}$, A. Damerau ${ }^{1,2}$, P. Hoff ${ }^{1}$, F. Buttgereit ${ }^{1,2}$, T. Gaber ${ }^{1,2},{ }^{1}$ Charité - Universitätsmedizin Berlin, corporate member of Freie Universität Berlin, Humboldt-Universität zu Berlin, and Berlin Institute of Health, Department of Rheumatology and Clinical Immunology, Berlin, Germany; ${ }^{2}$ German Rheumatism Research Centre (DRFZ) Berlin, a Leibniz Institute, Berlin, Germany; ${ }^{3}$ Quanzhou First Hospital Affiliated to Fujian Medical University, Department of Gastroenterology, Quanzhou, China; ${ }^{4}$ Julius-Maximilians Universität Würzburg, Institut für Systemimmunologie, Würzburg, Germany
Background: Inflamm-aging is a chronic, sterile, low-grade inflammatory status, characterized by an increase of proinflammatory cytokines which participate in the development of most age-related diseases such as cancer, Alzheimer's disease, type 2 diabetes mellitus, stroke, cardiovascular diseases, and rheumatoid arthritis (RA). As cellular metabolism modulates $T$ cell function, it can be assumed that metabolic changes accompany the differentiation of memory CD4+ $T$ cells into senescent $C D 4+T$ cell and contribute to memory $C D 4+T$ cells dysfunction during aging.

Objectives: Therefore, we hypothesized that metabolic reprograming in memory CD4+ T cells might represent an essential factor promoting immune cell dysfunction during aging, thereby fuelling to the pathogenesis of age-related diseases including RA

Methods: To this end, we analysed memory CD4+ T cells isolated from PBMCs of young donors (20-32 years) and old donors (52-67 years) by using MAC$\mathrm{S}^{\mathrm{TM}}$ technology. Ex vivo memory CD4+ T cells were analysed by Seahorse ${ }^{\mathrm{TM}}$ Technology to determine proton efflux rate (PER) as a measure of glycolysis (glycPER) and oxygen consumption rate (OCR) as a measure of mitochondrial respiration (mitoOCR). Cytokine expression and secretion was measured by flow cytometry and multiplex assay with and without Mitotempo an inhibitor of reactive oxygen species (ROS). Finally, TCR-stimulated memory CD4+ T cell proliferation was determined using CSFE and Ki-67 after 3 days and 4 days by flow cytometry. ROS and mitochondrial activity were analysed after $24 \mathrm{~h}$ using DCF-DA and CellROX Deep Red and Mitotracker by flow cytometry.

Results: In a quiescent state, memory $\mathrm{CD} 4^{+} \mathrm{T}$ cells from elderly individuals demonstrated a decrease in basal glycolysis and compensatory glycolysis, and an increase in the ratio of basal mitochondrial oxygen consumption rate (mitoOCR) to glycolytic proton efflux rate (glycoPER) while their mitochondrial profile was equivalent to that of young donors while the amount of mitochondria was higher with no increase in steady-state ATP level. In this line and in comparison to the younger reference group, memory $\mathrm{CD}^{+} \mathrm{T}$ cells from aged donors presented a greater spare respiratory capacity after TCR-activation and a marked increase in intracellular ROS production. Interestingly, we did not observe an impact of aging on memory $\mathrm{CD} 4^{+} \mathrm{T}$ cell proliferation as determined by CFSE and Ki-67. Although the capacity of intracellular cytokine expression did not diffe between the compared groups, the levels of secreted IFN- $\gamma$, IP-10, IL-6, IL-9, and MCAF were significantly higher in the supernatants of memory $\mathrm{CD} 4^{+} \mathrm{T}$ cells taken from aged donors but were sensitive to ROS inhibition.

Conclusion: These findings suggest that metabolic reprogramming in human memory $\mathrm{CD} 4^{+} \mathrm{T}$ cells during aging results in an increased expression of proinflammatory cytokines as a result of ROS production and mitochondrial dysfunction. This process may culminate in T cell dysfunction and thus contribute to the pathogenesis of inflamm-aging and the development of age-related diseases such as rheumatoid arthritis (RA).

Disclosure of Interests: None declared.

DOI: 10.1136/annrheumdis-2021-eular.3937

\section{Hyperinflammation and Covid19}

\begin{tabular}{l|l}
\hline OP0313 & PRELIMINARY CRITERIA FOR MACROPHAGE \\
ACTIVATION SYNDROME ASSOCIATED WITH \\
CORONAVIRUS DISEASE-19
\end{tabular}

S. Amikishiyev ${ }^{1}$, M. G. Gunver ${ }^{2}$, M. Bektas ${ }^{1}$, S. Aghamuradov ${ }^{1}$, B. Ince ${ }^{1}$, N. Koca3, E. S. Torun ${ }^{1}$, N. Aliyeva ${ }^{1}$, S. Sarı ${ }^{1}$, C. Cetin ${ }^{1}$, B. Ç. Yalçın Dulundu', R. Deniz ${ }^{4}$, F. Kemik' ${ }^{4}$ B. F. Agargun 4 , U. A. Gulseren ${ }^{4}$, B. Besisik' ${ }^{4}$, O. Alkan ${ }^{4}$, C. Bağrıaçık ${ }^{4}$, Y. B. Tor ${ }^{4}$, Y. Catma ${ }^{4}$, G. Durak ${ }^{5}$, S. Mese ${ }^{6}$, A. Agacfidan ${ }^{6}$, M. Kose' ${ }^{4}$, M. Erelel ${ }^{7}$, A. A. Çağatay ${ }^{8}$, S. Ş. Yavuz ${ }^{8}$, S. K. Besısık ${ }^{9}$, F. Esen ${ }^{10}$, A. Gül1. ${ }^{1}$ Istanbul Faculty of Medicine, Istanbul University, Division of Rheumatology, Istanbul, Turkey; ${ }^{2}$ Istanbul Faculty of Medicine, Istanbul University, Department of Biostatistics, Istanbul, Turkey; ${ }^{1}$ Istanbul Faculty of Medicine, Istanbul University, Division of Rheumatology, Istanbul, Turkey; ${ }^{4}$ Istanbul Faculty of Medicine, Istanbul University, Department of Internal Medicine, Istanbul, Turkey; ${ }^{5}$ Istanbul Faculty of Medicine, Istanbul University, Department of Radiology, Istanbul, Turkey; 6 Istanbul Faculty of Medicine, Istanbul University, Department of Medical Microbiology, Division of Virology and Fundamental Immunology, Istanbul, Turkey; ${ }^{7}$ Istanbul Faculty of Medicine, Istanbul University, Department of Chest Diseases, Istanbul, Turkey; ${ }^{8} /$ stanbul Faculty of Medicine, Istanbul University, Department of Infectious Diseases and Clinical Microbiology, Istanbul, Turkey; ${ }^{9}$ Istanbul Faculty of Medicine, Istanbul University, Division of Hematology and Therapeutic Apheresis Unit, Istanbul, Turkey; ${ }^{10}$ Istanbul Faculty of Medicine, Istanbul University, Department of Anesthesiology, Istanbul, Turkey

Background: COVID-19 runs a severe disease associated with acute respiratory distress syndrome in a subset of patients, and a hyperinflammatory response developing in the second week contributes to the worse outcome. Inflammatory 
features are mostly compatible with macrophage activation syndrome (MAS) observed in other viral infections despite resulting in milder changes. Early detection and treatment of MAS may be associated with a better outcome. However, available criteria for MAS associated with other causes have not been helpful. Objectives: To identify distinct features of MAS associated with COVID-19 using a large database enabling to assess of dynamic changes.

Methods: PCR-confirmed hospitalized COVID-19 patients followed between March and September 2020 constituted the discovery set. Patients considered to have findings of MAS by experienced physicians and given anakinra or tocilizumab were classified as the MAS group and the remaining patients as the non-MAS group. The MAS group was then re-grouped as the cases with exactMAS and borderline-MAS cases by the study group. Clinical and laboratory data including the $\mathrm{Ct}$ values of the PCR test were obtained from the database, and dynamic changes were evaluated especially for the first 14 days of the hospitalization. The second set of 162 patients followed between September-December 2020 were used as the replication group to test the preliminary criteria. In the second set, hospitalization rules were changed, and all patients required oxygen support and received dexamethasone $6 \mathrm{mg} /$ day or equivalent glucocorticoids. Daily changes were calculated for the laboratory items in MAS, borderline, and non-MAS groups to see the days differentiating the groups, and ROC curves and lower and upper limits (10-90\%) of the selected parameters were calculated to determine the cutoff values.

Results: A total of 769 PCR-confirmed hospitalized patients were analysed, and 77 of them were classified as MAS and 83 as borderline MAS patients. There was no statistically significant difference in the baseline viral loads of MAS patients compared to the non-MAS group according to the Ct values. Daily dynamic changes in the MAS group differed from the non-MAS group especially around the $6^{\text {th }}$ day of hospitalization, and more than a twofold increase in ferritin and a 1.5-fold increase in D-dimer levels compared to the baseline values help to define the MAS group. Twelve items selected for the criteria are given in Table 1 below. The total score of 45 provided $79.6 \%$ sensitivity for the MAS (including borderline cases) and $81.3 \%$ specificity around days 5 and 6 in the discovery set, and a score of 60 increased the specificity to $94.9 \%$ despite a decrease in sensitivity to $40.8 \%$. The same set provided a similar sensitivity $(80.3 \%)$ in the replication, but a lower specificity $(47.4-66 \%$ on days 6 to 9$)$ due to a group of control patients with findings of MAS possibly masked by glucocorticoids.

Table 1. Preliminary Criteria for Macrophage Activation Syndrome Associated with Coronavirus Disease-19

1. Fever $\left(>37.0^{\circ} \mathrm{C}\right)$

2.Ferritin concentration $>550 \mathrm{ng} / \mathrm{mL}$

3.More than 2 times increase of ferritin concentration within 7 days of disease onset

4.Neutrophil count $>6000 \mathrm{cell} / \mathrm{mm}^{3}$

5.Lymphopenia $<1000 \mathrm{cell} / \mathrm{mm}^{3}$

6. Neutrophil/lymphocyte ratio $>6$

7.D-dimer concentration $>1000 \mathrm{ng} / \mathrm{ml}$

8.More than $50 \%$ increase of $\mathrm{D}$-dimer concentration within 7 days of disease onse

9.CRP concetration $>50 \mathrm{mg} / \mathrm{L}$

10. $\mathrm{LDH}$ concentration $>300 \mathrm{U} / \mathrm{L}$

11.ALT or AST concentration $>50 \mathrm{U} / \mathrm{L}$

12.Procalcitonin concentration $<1.2$

1 point for each positive item assessed on Days 5-7Score calculation: Total points / $12 \mathrm{x}$ 100 Possible MAS $\geq 45$ and Definite MAS $\geq 60$

Conclusion: This study defined a set of preliminary criteria using the most relevant items of MAS according to the dynamic changes in the parameters in a group of COVID-19 patients. A score of 45 would be helpful to define a possible MAS group with reasonable sensitivity and specificity to start necessary treatments as early as possible.

Disclosure of Interests: None declared.

DOI: 10.1136/annrheumdis-2021-eular.3113

\section{OP0314 DOCK8 MUTATIONS IN COVID-19 AND MIS-C CYTOKINE STORM SYNDROME}

R. Cron ${ }^{1}$, M. Zhang ${ }^{1}$, D. Absher ${ }^{2}$, J. Bridges ${ }^{1}$, A. Schnell ${ }^{3}$, P. Bhatraju ${ }^{4}$, A. Vagrecha ${ }^{5}$, S. Lozinsky ${ }^{6}$, S. Acharya ${ }^{7}$, C. Levy ${ }^{7}$, W. Chatham ${ }^{3} .{ }^{1}$ University of Alabama at Birmingham, Pediatrics, Birmingham, United States of America; ${ }^{2}$ HudsonAlpha Institute for Biotechnology, Genomic Health Research, Huntsville, United States of America; ${ }^{3}$ University of Alabama at Birmingham, Medicine, Birmingham, United States of America; ${ }^{4}$ University of Washington, Medicine, Seattle, United States of America; ${ }^{5}$ Hofstra University, Pediatrics, Hempstead, United States of America; ${ }^{6}$ Hofstra University, Neurosurgery, Hampstead, United States of America; ${ }^{7}$ Hofstra University, Pediatrics, Hampstead, United States of America

Background: We recently identified DOCK8 as a novel gene associated with cytokine storm syndrome (CSS) ${ }^{1}$. Heterozygous missense mutations in DOCK 8 diminish NK cell lytic function and contribute to increased pro-inflammatory cytokine production (CSS). CSS is a potential complication of COVID-19 with severe consequences ${ }^{2}$. Children are at risk of a SARS-CoV-2 post-infectious CSS, multisystem inflammatory syndrome in children (MIS-C) ${ }^{3}$. Host genetic factors associated with COVID-19 CSS and MIS-C CSS are unknown.

Objectives: The goals are to identify and functionally study rare mutations in DOCK8 in patients with SARS-CoV-2 COVID-19 and MIS-C

Methods: To date, 16 adult patients enrolled in a COVID-19 CSS clinical trial at UAB had whole genome sequencing. Four $(25 \%)$ had rare heterozygous DOCK8 mutations (3 missense, 1 intronic). A COVID-19 CSS adult patient in Seattle also had a $D O C K 8$ missense mutation. In addition, DOCK 8 missense mutations were identified in five children (UAB \& Northwell) hospitalized with MIS-C. DOCK8 mutations, or wild-type (WT) sequence controls, were introduced into human NK-92 cells by FOAMY virus transduction. WT and mutant DOCK8-expressing NK-92 cells were incubated with K562 target cells and compared for cytolysis and degranulation (CD107a).

Results: One COVID-19 patient DOCK8 mutation (Gly523Arg) reduced NK cell degranulation by $30 \%$ and cytolysis by $23 \%(n=3)$ (Figure 1$)$. Similar studies of 3 MIS-C patients with DOCK8 missense mutations (Arg899Trp, Ala2Thr, Pro$687 \mathrm{Leu}$ ) revealed up to $31 \%$ reduced NK cell degranulation and $48 \%$ reduction in cytolysis by 3 distinct mutations $(n=3)$. Two-way ANOVA analysis revealed statistically significant $(p<0.05)$ differences in NK cell degranulation and lysis for fou unique DOCK8 mutations.
A

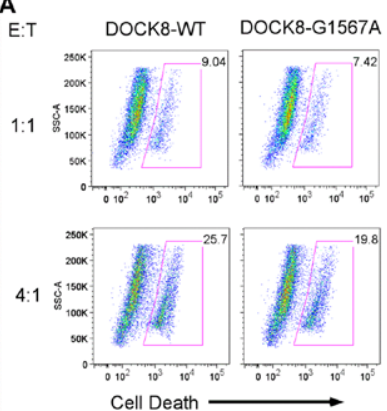

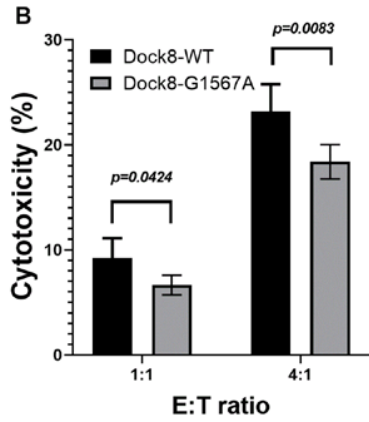

Conclusion: Heterozygous DOCK 8 missense mutations may contribute to severe COVID-19 and MIS-C CSS by partial dominant-negative effects yielding decreased NK cell cytolysis.

REFERENCES:

[1] Schulert GS, Cron RQ. The genetics of macrophage activation syndrome. Genes Immun 2020:21:169-181.

[2] Cron RQ, Chatham WW. The rheumatologist's role in COVID-19. J Rheumatol 2020:47:639-642.

[3] Reiff D, Mannion ML, Samuy N, Scalici P, Cron RQ. Distinguishing active pediatric COVID-19 from MIS-C. Pediatr Rheumatol Online J, in press.

Disclosure of Interests: Randy Cron Consultant of: SOBI, Novartis, Pfizer Sironax, Grant/research support from: SOBI, Mingce Zhang: None declared, Remy Cron: None declared, Devin Absher: None declared, John Bridges: None declared, Amanda Schnell: None declared, Pavan Bhatraju: None declared, Anshul Vagrecha: None declared, Shannon Lozinsky: None declared, Suchitra Acharya: None declared, Carolyn Levy: None declared, Winn Chatham Grant research support from: SOBI.

DOI: 10.1136/annrheumdis-2021-eular.1865

\section{Metabolic pathways during the regulation of inflam- mation and immunity}

\section{\begin{tabular}{|l|l}
\hline OP0315 & EFFECTOR CD4 T CELLS REQUIRE SURVIVIN FOR
\end{tabular} REGULATION OF GLUCOSE METABOLISM AND IFNG PRODUCTION}

M. Erlandsson ${ }^{1,2}$, K. M. Andersson ${ }^{1}$, N. Oparina ${ }^{1}$, S. Töyrä Silfverswärd ${ }^{1}$, M. I. Bokarewa ${ }^{1,2} .{ }^{1}$ Gothenburg University, Rheumatology and Inflammation Research, Gothenburg, Sweden; ${ }^{2}$ Sahlgrenska University Hospital, Rheumatology clinic, Göteborg, Sweden

Background: Interferon-gamma (IFNg) producing effector T cells play the leading role in triggering and perpetuation of inflammation in rheumatoid arthritis. Inflammation leads to metabolic reprogramming of T cells and high energy consumption supporting proliferation and IFNg production. Being a part of chromosomal passenger complex, oncoprotein survivin is essential for cell proliferation It has also been identified as a marker of severe therapy-resistant rheumatoid 